\title{
Association of folic acid and vitamin B12 deficiency in children with iron deficiency anaemia
}

\author{
Chithambaram N S', D'Souza Joy L $\mathbf{P}^{2}$ \\ ${ }^{1}$ Dr Chithambaram Nagalingam Saroja, Associate Professor, Department of Pediatrics, Vydehi Institute of Medical \\ Sciences and Research Centre, Bangalore, Karnataka, ${ }^{2}$ Dr Joy L P D'Souza, Associate Professor, Department of \\ Pediatrics, Vydehi Institute of Medical Sciences and Research Centre, Bangalore, Karnataka, India.
}

Address for Correspondence: Dr N S Chithambaram, Email : paedia_chithambaram85@ vimsmail.com.

\begin{abstract}
Objective: To find out the association of folic acid and vitamin $\mathrm{B}_{12}$ deficiency in patients with iron deficiency anaemia in Indian children admitted to a tertiary hospital. Design: Observational cross sectional study. Setting: Tertiary-level hospital from October 2010-September 2011, for a period of one year. Participants: All children aged between 6 months to 13 years, admitted in paediatric ward of this hospital for any complaints, were evaluated for anaemia. All patients with Hemoglobin levels less than the WHO cut off levels for anaemia were included in the study. Those who were sick and those who were on drugs, other conditions causing bone marrow suppression were excluded from the study. Methods: Serum iron, serum iron binding capacity, serum ferritin, serum vitamin B12, and serum folic acid analyses were conducted with autoanalyzers using commercial kits. Results: Out of 975 children who were admitted during the above period, 100 (34 females and 66 males) anemic children were included in the study. 2 patients were excluded as one child was diagnosed with Thalassemia minor and another patient was diagnosed as acute lymphoblastic Leukemia. Hence 98 children were taken up for study. Iron and Folic acid Deficiency observed in $6.12 \%(6 / 98)$, Iron and vitamin $\mathrm{B}_{12}$ Deficiency in $3.06 \%$ (3/98), Folic acid and vitamin $B_{12}$ Deficiency in $1.02 \%$ (1/98), Iron, Folic acid and vitamin $B_{12}$ Deficiency in $1.02 \%$ (1/98) of patients. Conclusions: Iron deficiency anaemia coexist with vitamin $\mathrm{B}_{12}$ and folate deficiency, but their association with iron deficiency anemia was not significant in our study.
\end{abstract}

Keywords: Anaemia, Folic acid deficiency, Iron deficiency, Vitamin $\mathrm{B}_{12}$ deficiency.

\section{Introduction}

Anaemia is a major public health problem all over the world especially in developing countries. The third National Family Health Survey (NFHS - 3) (2005-06) found that the prevalence of anaemia among under 5 children approaches $70 \%$ even though there is a national programme to control anaemia for many years [1]. The irreparable damage that anemia in childhood can cause particularly to the development of a young child on one hand and the knowledge and mechanism available for its control on the other, makes this silent morbidity completely unacceptable in modern times where we strive for millennium development Goal 4 [2]. Out of all the causes, nutritional anaemias account for the major cause of anaemias. Pregnant women, infants, young children and adolescents are at a higher

Manuscript received: $8^{\text {th }}$ April 2016

Reviewed: $20^{\text {th }}$ April 2016

Author Corrected; $4^{\text {th }}$ May 2016

Accepted for Publication: $15^{\text {th }}$ May 2016 risk of nutritional anaemia as they have a high demand of nutrients such as iron, folic acid, vitamin $\mathrm{B}_{12}$ and other nutrients. Nutritional anaemia is seen in almost one billion people all over the world and commonest being iron deficiency anemia [3]. Anaemia in children results in impaired cognitive performance, behavioral and language development and scholastic achievement. Anaemia is also associated with increased mortality and morbidity from infectious diseases [4]. Other causes of anemia include chronic infections, particularly malaria, hereditary hemoglobinopathies and folic acid deficiency. It is worth noting that multiple causes of anemia can coexist in an individual or in a population and contribute to the severity of the anemia.

The term 'nutritional anemia' encompasses all pathological conditions in which the blood hemoglobin concentration drops to an abnormally low level, due to a 
deficiency in one or several nutrients. The main nutrients involved in the synthesis of hemoglobin are iron, folic acid, and vitamin $\mathrm{B}_{12}$. In public health terms, iron deficiency is by far the first cause of nutritional anemia worldwide. Folic acid deficiency is less widespread and is often observed with iron deficiency. Vitamin $B_{12}$ deficiency is far rarer and it occurs mainly in vegetarians [5]. There are various studies done to find out the prevalence of iron deficiency anaemias in paediatric population in India and other developing countries $[6,7,8,9]$. But there is paucity of studies using laboratory measurements to find out the exact cause of nutritional anaemia and to find out the association of folic acid and vitamin $B_{12}$ deficiency in patients with iron deficiency anaemia in Indian population [10]. Hence this study was done with the objective to study the association of folic acid and vitamin $B_{12}$ deficiency in patients with iron deficiency anaemia in Indian children admitted to a tertiary hospital.

\section{Materials and Methods}

This study is an observational cross sectional study, conducted in paediatric ward of Vydehi Institute of Medical Sciences and Research Centre, a tertiary care hospital in southern India from October 2010September 2011 for a period of one year. Informed consent was taken from the care takers of the patients for this study. Permission was taken from the Ethics committee of the hospital for this study. All patients admitted in paediatric ward of this hospital for any complaints were evaluated for anaemia. Those patients who were less than 6 months of age, sick patients and those patients who were on drugs, other conditions causing bone marrow suppression were excluded from the study. All other patients with Hemoglobin levels less than the WHO cut off levels for anaemia were included in the study. WHO Expert group proposed that anaemia should be considered to exist when Hemoglobin is below the following levels in venous blood. 6 months to 6 years $11 \mathrm{gm} / \mathrm{dl}$, less than $12 \mathrm{~g} / \mathrm{dL}$ for girls from 6 to 18 yrs and boys from 6 to 14 years, and less than $13 \mathrm{~g} / \mathrm{dl}$ for boys from 15 to $18 \mathrm{yrs}$ of age [11].

In those patients found to have anaemia, the following laboratory investigations were done like mean corpuscular volume (MCV), mean corpuscular hemoglobin $(\mathrm{MCH})$, mean corpuscular hemoglobin concentration (MCHC), serum ferritin, serum iron, total iron binding capacity (TIBC), serum transferrin (TRF), serum folate assay and serum vitamin $B_{12}$ assay. $5 \mathrm{ml}$ of blood was collected in a EDTA tube for the study. Serum hemoglobin was estimated by spectrophotometric method by automated machine, serum ferritin by Chemiluminescent immunoassay, serum iron by Ferrozine_no deproteinization, TIBC by ion exchange resin ferrozine method, serum transferrin (TRF) by rate nephelometry, serum folate assay and vitamin $B_{12}$ assay by Chemiluminescent immunoassay. In case they were suffering from acute infective or inflammatory conditions [12] the above investigations were done after 3 afebrile days. The normal values for various study parameters in this study were considered from Nelson Text Book of Pediatrics [13].

\section{Results}

100 patients with anaemia as defined by WHO, admitted in the paediatric ward from the period from October 2010September 2011, were included in the study. The age of the patients ranged from 6 months to 13 years (Table 1). There were $66(66 \%)$ boys and34 (34\%) girls in the study population. 2 patients were excluded as one child was diagnosed with Thalassemia minor and another patient was diagnosed as Acute lymphoblastic Leukemia. The haemoglobin levels of the study subjects are mentioned as per Table 2, which shows that $69 \%$ had Hb levels between $10-12 \mathrm{~g} / \mathrm{dl}, 15 \% \mathrm{had} 9$ $10 \mathrm{~g} / \mathrm{dl}, 6 \%$ between $8-9 \mathrm{~g} / \mathrm{dl}, 5 \%$ between $7-8 \mathrm{~g} / \mathrm{dl}$ and $3 \%$ less than $7 \mathrm{~g} / \mathrm{dl}$. Levels of blood folate, serum B12, serum ferritin, serum Iron, TIBC and serum transferrin levels of patients studied are mentioned as per Table 3 which shows $16.3 \%$ had folic acid deficiency, 7.1\% had B12deficiency and 43.8\% had iron deficiency. Incidence of Iron deficiency anemia in our study was $54.1 \%$, Folic Acid deficiency was seen in $16.3 \%$ and Vitamin B12deficiency anemia was seen in $13.2 \%$ (Table 4).

Table-1: Age wise distribution of Patients under study.

\begin{tabular}{|l|l|l|l|l|l|}
\hline Patients age in years & $<1$ & $1-2$ & $2-5$ & $5-10$ & $>10$ \\
\hline No. of cases & 10 & 21 & 20 & 25 & 22 \\
\hline
\end{tabular}

Mean Age \pm SD: $6.03 \pm 4.28$ 
Table-2: Hemoglobin levels of patients studied.

\begin{tabular}{|l|l|l|l|l|l|}
\hline Haemoglobin levels in gms/dl & $<7$ & $7-8$ & $8-9$ & $9-10$ & $10-12$ \\
\hline No. of cases & 3 & 5 & 6 & 15 & 69 \\
\hline
\end{tabular}

Total children admitted 975

$\downarrow$

Anaemia cases included for the study $=100$

$\downarrow$

2 Excluded (Thalassemia minor - 1,ALL - 1)

$\downarrow$

Cases taken up for the study $=98$

Nutritional causes $(n=70)$

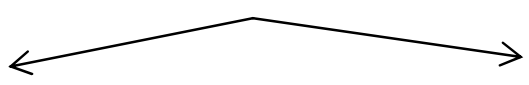

- Only Iron Deficiency

$-43(43.8 \%)$

$-8(8.16 \%)$

$-8(8.16 \%)$

$-1(1.02 \%)$

$-6(6.12 \%)$

$-3(3.06 \%)$

- Iron and vitamin $B_{12}$ Deficiency

$-1(1.02 \%)$

Table-3: Levels of Blood folate, serum B12 serum ferritin, Serum Iron, TIBC and Serum transferrin levels of patients studied.

\begin{tabular}{|c|c|c|c|c|c|c|}
\hline Hematological & No. of & Range & \multicolumn{4}{|c|}{ Distribution } \\
\hline $\begin{array}{c}\text { Blood Folate } \\
\mathrm{pg} / \mathrm{ml}\end{array}$ & 98 & $2.4->20$ & $\begin{array}{c}<4 \\
16(16.3)\end{array}$ & $\begin{array}{c}\text { 5- 10 } \\
60(61.2)\end{array}$ & $\begin{array}{l}\mathbf{1 0 - 1 5} \\
20(20.4)\end{array}$ & $\begin{array}{c}>\mathbf{1 5} \\
2(2.04)\end{array}$ \\
\hline $\begin{array}{c}\text { Serum B12 } \\
\mathrm{ng} / \mathrm{ml}\end{array}$ & 98 & $82->1500$ & $\begin{array}{c}<\mathbf{1 4 0} \\
7(7.1)\end{array}$ & $\begin{array}{c}140-202 \\
6(6.1)\end{array}$ & $\begin{array}{c}\mathbf{2 0 3 - 8 0 0} \\
83(84.7)\end{array}$ & $\begin{array}{c}>\mathbf{8 0 0} \\
2(2.04)\end{array}$ \\
\hline $\begin{array}{c}\text { Serum Iron } \\
\mathrm{mcg} / \mathrm{dl}\end{array}$ & 98 & $7-284$ & $\begin{array}{c}<22 \\
29(29.6)\end{array}$ & $\begin{array}{c}\mathbf{2 2 - 5 0} \\
36(36.7)\end{array}$ & $\begin{array}{c}>\mathbf{5 0} \\
33(33.7 .1)\end{array}$ & \\
\hline $\begin{array}{c}\text { TIBC } \\
\mathrm{mcg} / \mathrm{dl}\end{array}$ & 98 & $187-636$ & $\begin{array}{c}<250 \\
8(8.2)\end{array}$ & $\begin{array}{l}250-400 \\
46(46.7)\end{array}$ & $\begin{array}{c}>400 \\
44(44.9)\end{array}$ & \\
\hline Serum Ferritin $\mathrm{mcg} / 1$ & 98 & $2.2-711$ & $\begin{array}{c}<7 \\
13(13.3)\end{array}$ & $\begin{array}{c}\text { 7-140 } \\
74(75.5)\end{array}$ & $\begin{array}{c}>\mathbf{1 4 0} \\
11(11.2)\end{array}$ & \\
\hline $\begin{array}{c}\text { Serum Transferrin } \\
\mathrm{mg} / \mathrm{dl}\end{array}$ & 75 & $17-578$ & $\begin{array}{c}<95 \\
2(2.7)\end{array}$ & $\begin{array}{c}\mathbf{9 5 - 3 8 5} \\
58(77.3)\end{array}$ & $\begin{array}{c}>385 \\
15(20)\end{array}$ & \\
\hline
\end{tabular}

(Numbers in parenthesis are the percentages)

Serum transferrin could be done in only 75 patients because of the non-availability of kits during the study period. 
Table-4: Incidence of Iron deficiency, Folic Acid levels, and Vitamin B12 levels of patients studied.

\begin{tabular}{|c|c|c|}
\hline Iron deficiency & No. of patients & Percent \\
\hline Yes & 53 & 54.1 \\
\hline No & 45 & 45.9 \\
\hline Total & 98 & 100.0 \\
\hline \multicolumn{3}{|l|}{ Folic Acid } \\
\hline$<4$ & 16 & 16.3 \\
\hline $4-15$ & 80 & 81.6 \\
\hline$>15$ & 2 & 2.04 \\
\hline Total & 98 & 100.0 \\
\hline \multicolumn{3}{|l|}{ Vitamin $B_{12}$} \\
\hline$<203$ & 13 & 13.2 \\
\hline 203-800 & 83 & 84.7 \\
\hline$>800$ & 2 & 2.04 \\
\hline Total & 98 & 100.0 \\
\hline
\end{tabular}

\section{Discussion}

The results of the present study showed that out of 98 children with anaemia, nutritional anaemia was noted in $71.4 \%(70 / 98)$ of the children. Pure iron deficiency anaemia (IDA) was detected in 43.8 per cent (43/98) of anaemic children. Vitamin B12 deficiency alone or in combination with iron was diagnosed in $8.16 \%(8 / 98)$ and $3.06 \%$ (3/98) anaemic children respectively. Similarly folate deficiency alone or in combination with IDA was $8.16 \%$ and $6.1 \%(6 / 98)$ respectively. $1 \%$ (1/98) had all, iron, folic acid and Vitamin B12 deficiency. Pasricha et al [14] in 2011, studied the micronutrients such as vitamin $\mathrm{B}_{12}$, folate, iron and vitamin A concentrations of 396 children in the age group of $12-23$ months in rural Karnataka in south India. They found that $65.6 \%$ had at least one micronutrient deficiency and those children between 12 years who are breast feeding should be targeted during micronutrient supplementation programs. Ahmed F et al [15] in 2008 studied the prevalence of selected micronutrient deficiencies amongst anaemic adolescent school girls in rural Bangladesh, and they found that $28 \%$ of the girls had depleted iron stores, $25 \%$ had folic acid deficiency, $89 \%$ had vitamin $\mathrm{B}_{2}$ and $7 \%$ had vitamin $\mathrm{B}_{12}$ deficiencies.

They concluded that there is coexistence of micronutrient deficiencies among anaemic adolescent girls in rural Bangladesh, although they do not suffer from energy deficiency. Of all micronutrients only iron and vitamin $\mathrm{B}_{2}$ concentrations were found to be related to the $\mathrm{Hb}$ concentration. Gadowsky SLet al [16] estimated the prevalence of biochemical iron, folate, and vitamin $\mathrm{B}_{12}$ depletion among a group of Canadian pregnant adolescents. They found that $22 \%$ of the pregnant adolescents had anaemia, $78 \%$ had depleted iron stores and $25 \%$ had plasma vitamin $\mathrm{B}_{12}$ values in the sub-optimal range. Metz J [17] reviewed the prevalence of anemia based on biochemical evidence. $\mathrm{He}$ found that the overall contribution of vitamin $\mathrm{B}_{12}$ deficiency to the global burden of anemia was not significant, except in women and their infants and children in vegetarian communities.

He also found that it was unlikely that folate deficiency makes a major contribution to the burden of anemia in developing countries. Iron-deficiency anemia may coexist with vitamin $\mathrm{B}_{12}$ and especially folate deficiency, and may confound the hematological features of the vitamin deficiencies whose prevalence would then be underestimated. Van der Westhuyzen Jet al [18] investigated the prevalence of anaemia and deficiencies of iron, folate and vitamin $\mathrm{B}_{12}$ in 140 rural black preschool children aged 3-5 years living in five different villages in the Letaba area, near Tzaneen. $39.2 \%$ were anaemic having hemoglobin levels below $11.1 \mathrm{~g} / \mathrm{dl}$.

Approximately $10 \%$ were considered to be irondeficient. On the basis of subnormal red cell folate values, 1 in 4 children was folate-deficient, and suggested the need for intervention at the community level such as enrichment of the staple foodstuff, maize 
meal with folic acid. Some limitations in our study should be considered. Firstly, this study was conducted in hospitalized patients and hence the results in this study are not a true representative of the general population. Secondly, this study did not measure vitamin A. There are studies which showed that children with iron deficiency anemia had more frequently low serum retinol [14,19] but its potential contribution as a cause of nutritional anemia in this study was not estimated. Thirdly, quantitative estimation of CRP was not done, which would have identified false positive elevation of serum ferritin. It is possible that ferritin values, especially those in the neighborhood of the cut-off point were increased by acute inflammation [20,21].

Fourthly, the measurements of metabolites such as homocysteine and methylmalonoic acid may have identified the functional deficiencies of vitamin B 12 and folic acid. Finally the sample size of this study is small and hence the results of this study could not be generalized to the whole population even though our hospital catered to patients from all over the country. Hence further studies are recommended to formulate a policy in treating those patients with nutritional anaemias.

\section{Conclusion}

Anaemia continues to be a public health program in children in India. Iron deficiency either alone or in combination is the commonest nutritional cause of anaemia. Iron deficiency anemia and its association with folic acid deficiency and vitamin $\mathrm{B}_{12}$ deficiency were not significant in our study. Pure or mixed folic acid and vitamin B12 deficiency are important but not commonly recognized cause of anaemia in these children.

Acknowledgements: We would like to acknowledge Dr (Mrs) Kalpaja DA, Director of VIMS \& RC, Dr (Mrs) Kantha S, Advisor of VIMS \& RC, for allowing us to do the study. We also acknowledge "BeckmanCoultar" company for providing the kits for this study.

Funding: Nil, Conflict of interest: Nil

Permission from IRB: Yes

\section{References}

1. International Institute for Population. Sciences (IIPS) and Macro International. 2007. National Family. Health Survey (NFHS-3), 2005-06: India: 290-291.
2. Prakash V Kotecha. Nutritional Anemia in Young Children with Focus on Asia and India. Indian $\mathrm{J}$ Community Med 2011; 36(1): 8-16.

3. Administrative Committee on Co-ordinationSubcommittee on nutrition (ACC-SCN) (1992) Second report on the world nutrition situation,Vol, Global and regional results. Geneva, United Nations;40-48.

4. V.Sethi, G.Goindi and U.Kapil.. 2003;70:. Prevalence of Anaemia amongst primary school age children (6-11 years) in National Capital Territory of Delhi. Indian J Pediatr 2003; 70(): 519-20.

5. Asok c Antony. Vegetarianism and vitamin B 12 (cobalamin) deficiency. The Am $\mathrm{J}$ clin nutr 2003;78(1):3-6.

6. Sabita Basu, Srikanta Basu, Ranjitha Hazarika et al. Prevalence of anaemia among school going adolescents of Chandigarh. Indian Pediatr 2005; 42(6): 593-597.

7. Gomber S, Kumar S, Rusia U et al. Prevalence \& etiology of nutritional anaemias in early childhood in an urban slum. Indian J Med Res 1998;107:269-273.

8. Gomber S, Bhawna, Nishi $\mathrm{M}$ et al. Prevalence \& etiology of nutritional anaemia among school children of urban slum. Indian J Med Res 2003;118:169-171.

9. Deeksha Kapur, Kailash N. Agarwal, Sushma et al. Iron Status of Children Aged 9-36 Months in an Urban Slum Integrated Child Development Services Project in Delhi. Indian Pediatr 2002;39:136-144.

10. Singh P, Toteja G S. Micronutrient profile of Indian children and women:Summary of available data for iron and vitamin A. Indian Pediatr 2003;40:477-479.

11. WHO/UNICEF/UNU 2001. Iron deficiency anemia :Assessment, prevention and control. A guide for programme managers. Available from: http//www.who. int/nut/documents/ida_assessment_ prevention_control. Accessed May 26th 2003.

12. Kung'u JK, Wright VJ, Haji HJ, Ramsan M, Goodman D, Tielsch JM, et al. Adjusting for the acute phase response is essential to interpret iron status indicators among young Zanzibari children prone to chronic malaria and helminth infections. J Nut. 2009; 139(11):2124-2131. 
13. Richard Sills. Iron-Deficiency Anemia. Kliegman, Behrman, Bonita F.S, Joseph W, Nina.F.S (eds). Nelson Textbook of Pediatrics, 20th e-edition vol.2 ed. Canada: Elsevier; 2016. pp. 2323-2326.

14. Pasricha S,Arun S S, James F B,Sudarshan H, Prashanth NS and Beverley-Ann B. Vitamin B-12, folate,iron and vitamin A concentrations in rural Indian children are associated with continued breast feeding, complementary diet and maternal nutrition. Am J Clin Nutr 2011;94 (5):1358-1370.doi:10.3945/ajcn.111. 018580

15. Ahmed F, Khan MR, Banu CP, Qazi MR, Akhtaruzzaman M. The coexistence of other micronutrient deficiencies in anaemic adolescent school girls in rural Bangladesh. Eur J Clin Nut. 2008; 62(3):365-372.

16. Gadowsky SL, Gale K, Wolfe SA, Jory J, Gibson R, O'Connor DL. Biochemical folate, B12, and iron status of a group of pregnant adolescents accessed through the public health system in southern Ontario. J Adolesc Health 1995;16(6):465-474.

17. Metz J.A high prevalence of biochemical evidence of vitamin B12 or folate deficiency does not translate into a comparable prevalence of anemia. Food Nutr Bull 2008;29(Suppl):S74-85.

18. van der Westhuyzen J, van Tonder SV, Gilbertson I, Metz J.Iron, folate and vitamin B12 nutrition and anaemia in black preschool children in the northern Transvaal. S Afr Med J. 1986;70(3):143-146.

19. Villalpando S, Perez-Exposito AB, Shamah-Levy T, Rivera JA. Distribution of anemia associated with micronutrient deficiencies other than iron in a probabilistic sample of Mexican children. Ann Nutr Metab 2006;50(6):506-511.

20. L Hulthén, G Lindstedt, P-A Lundberg and L Hallberg. Effect of a mild infection on serum ferritin concentration clinical and epidemiological implications. European journal of clinical nutrition 1998;52(5):376379

21. Saraya AK, Choudhary VP, Ghai OP. Interrelationship of vitamin B 12, folic acid and iron in anaemia of infancy and childhood:effect of vitamin B 12 and iron therapy on folate metabolism. Am J Clin Nutr 1973;26(3):640-646.

\section{How to cite this article?}

Chithambaram N S, D'Souza Joy L P. Association of folic acid and vitamin B12 deficiency in children with iron deficiency anaemia. Int J Pediatr Res.2016;3(5):358-363.doi:10.17511/ijpr.2016.i05.16 